\title{
Limited liver resection of a giant hepatic hemangioma is based on graft to recipient weight ratio, a case report
}

gaofeng Tang ${ }^{1}$, Bing Wang ${ }^{1}$, shaotang zhou ${ }^{1}$, and guoyong chen ${ }^{1}$

${ }^{1}$ Affiliation not available

April 28, 2020

\begin{abstract}
Aims: Major or limited liver resection of giant benign or malignant tumor is clinically challenging relating residual liver volume to. Here we reported a case of limited liver resection basing on graft to recipient weight ratio. Methods: A giant hepatic hemangioma was detected in a 36 year-old female patient using ultrasound and computerized tomography. His normal liver to total volume ratio was about $20 \%$. We calculated that her remnant liver to body weight ratio was $1.61 \%$, sufficient to support her body, so limited liver resection was conducted. Results: The patient went through a uneventful recovery, she was discharged home 11 days after liver resection and has been well on regular followup. Conclusions: Limited liver resection is feasible in technique following graft to recipient weight ratio.
\end{abstract}

\section{Hosted file}

draft - new.doc available at https://authorea.com/users/309246/articles/440206-limited-liverresection-of-a-giant-hepatic-hemangioma-is-based-on-graft-to-recipient-weight-ratio-a-casereport 


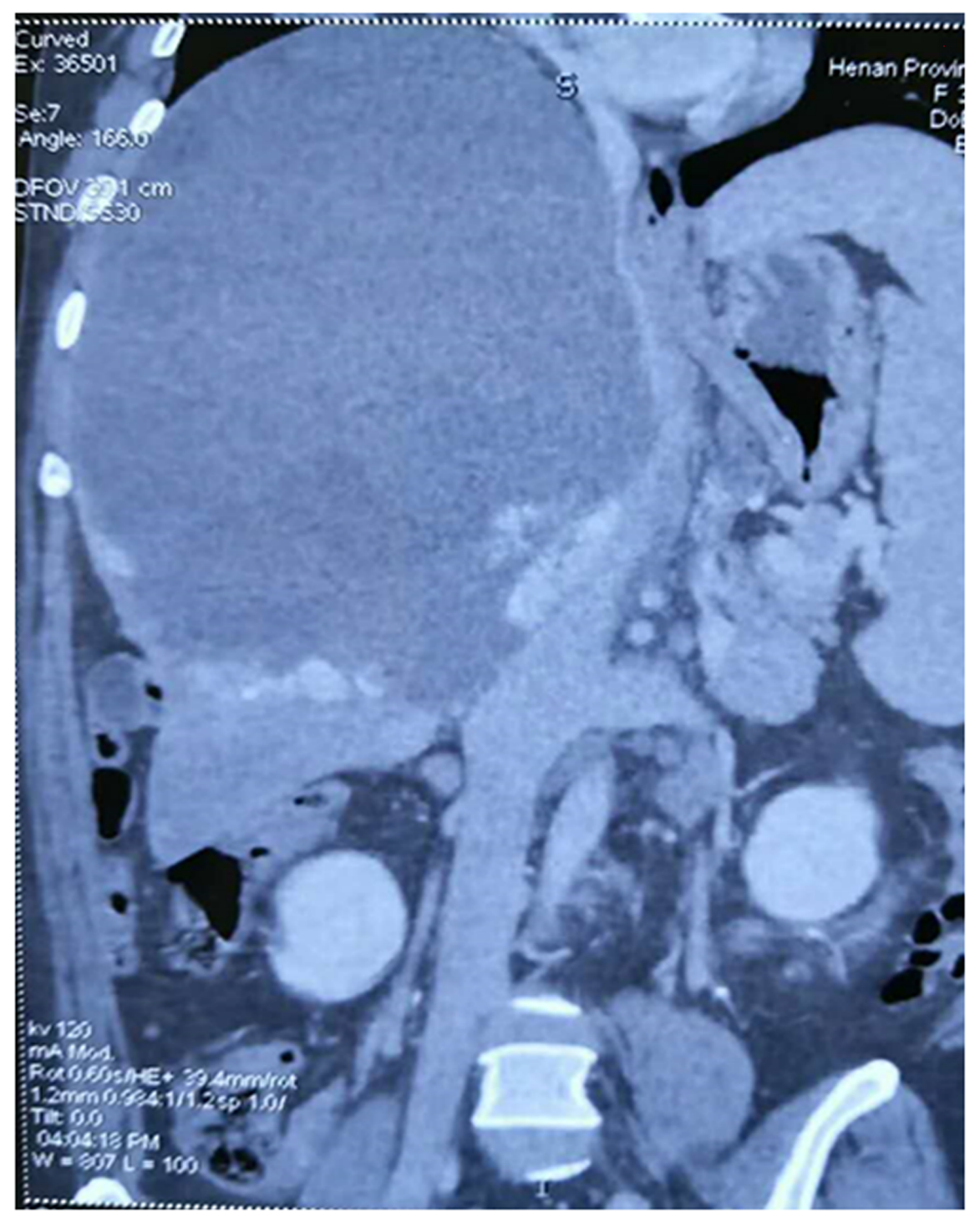




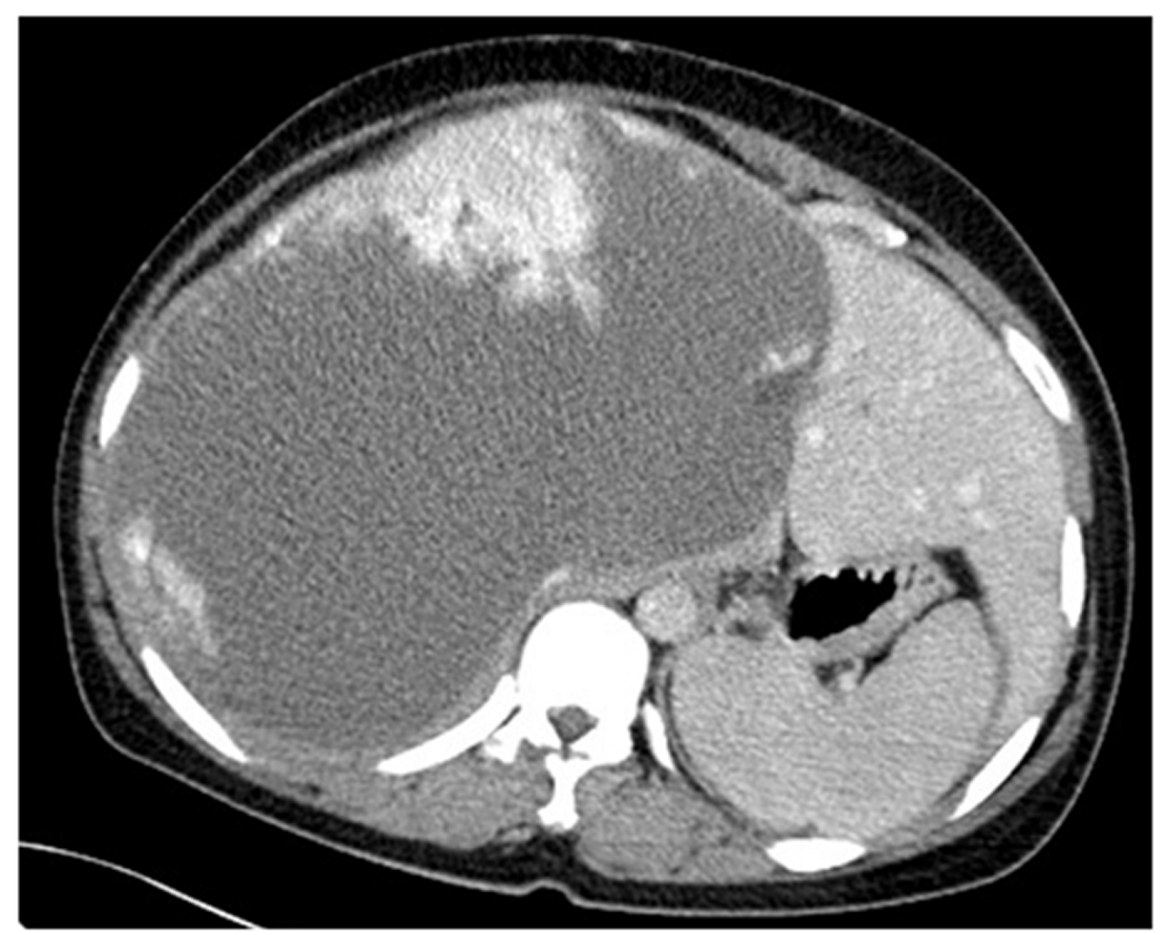

